\title{
Creativos, divertidos, emprendedores y meritocráticos El trabajo en contexto de las tecnologías de la información
}

Hernán M. Palermo y yatricia Ventrici

${ }^{1}$ Centro de Estudios e Investigaciones Laborales (CEIL). CONICET. Buenos Aires, Argentina. ORCiD: 0000-0003-0414-7352

Correo electrónico: hernanpalermo@gmail.com

${ }^{2}$ Centro de Estudios e Investigaciones Laborales (CEIL). CONICET. Buenos Aires, Argentina. ORCiD: 0000-0003-4970-7720

Correo electrónico: patriciaventrici@gmail.com

\section{Recibido}

agosto de 2019

Aceptado

mayo de 2020

doi: 10.34096/cas.i52.6905

\section{Resumen}

El propósito del presente artículo es analizar la fuerza de trabajo que se produce y reproduce en un contexto laboral signado por la tecnología digital, en particular, en la empresa estrella en e-commerce de Latinoamérica: Mercado Libre. Específicamente, nos interesa abordar las significaciones acerca del trabajo que realizan los trabajadores y las trabajadoras, comprendiendo que estas se encuentran en una tensión constante entre las políticas empresarias, los procesos de pedagógicos de producción de una determinada fuerza de trabajo y las agencias de los sujetos. En este espacio laboral, el emprendedurismo y la meritocracia se perfilan como los sentidos dominantes en relación con la idea trabajo. Asimismo, indagamos las tensiones que se suscitan en la construcción gremial: sus desafíos, estrategias y limitaciones en una empresa donde la construcción managerial normativiza una noción de individuo como primera y última finalidad.

\section{Creatives, fun, entrepreneurs and meritocratic. Work in the context of information technologies}

\footnotetext{
Abstract

This article aims to analyze the work force that is produced and reproduced in a labor context marked by digital technology. In particular, we focus on the leading e-commerce company in Latin America: Mercado Libre. Specifically, we are interested in addressing worker's meanings about work, understanding that they are in constant tension between business policies, business pedagogical processes and the agency of subjects. In
}

\section{Palabras clave}

Capitalismo cognitivo; Nuevas formas del trabajo; Informática; Sindicalismo; Mercado LibreArgentina

\section{Key words}

Cognitive Capitalism; New Forms of Work; Informatics; Trade Unionism; Mercado LibreArgentina 
this workspace, entrepreneurship and meritocracy emerge as the dominant meanings in relation to the idea of work. Likewise, we examine the tensions that arise in union construction: its challenges, strategies and limitations in a company where managerial construction standardizes a notion of the individual as the first and last purpose.

\section{Criativos, engraçados, empreendedores e meritocráticos. $\mathrm{O}$ trabal- ho no contexto das tecnologias da informação}

\section{Resumo}

Palavras-chave

Capitalismo cognitivo; Novas formas de trabalho; Informática; Sindicalismo; Mercado LibreArgentina
O objetivo deste artigo é analisar a força de trabalho que é produzida e reproduzida em um contexto de trabalho marcado pela tecnologia digital, em particular, na principal empresa de comércio eletrônico da América Latina: o "Mercado Libre”. Especificamente, estamos interessados em abordar os significados sobre o trabalho que os funcionários fazem, entendendo que eles estão em constante tensão entre as políticas de negócios, os processos pedagógicos de produção de uma determinada força de trabalho e os próprias agências. Neste espaço de trabalho o empreendedorismo e a meritocracia estão emergindo como os sentidos dominantes em relação à ideia de trabalho. Da mesma forma, investigamos as tensões que surgem na construção do sindicato: seus desafios, estratégias e limitações em uma empresa onde a construção gerencial padroniza a noção do indivíduo como primeira e última finalidade.

\section{Introducción}

“Lo que permite la empresa star-up es una revitalización del liberalismo, pero bajo su forma tecnolibertaria. Le ofrece un tratamiento inoculándole un rejuvenecedor que modifica en apariencia su naturaleza, entregándole un certificado de virginidad y ornamentándolo con un brillo histórico inédito". (Eric Sadin, 2018: 154)

¿Qué significa trabajar en un contexto atravesado por la tecnología de la información? En primer lugar, podemos plantear que hay un aspecto que se ha homogeneizado: aquel momento en el que nos sentamos ante una pantalla y tecleamos. En este aspecto físico, el trabajo se ha vuelto casi indiferenciado. No obstante, en el acto de teclear se despliegan una serie de saberes cognitivos que hacen del trabajo una práctica completamente diferenciada, específica y particular. Algunos autores plantean que el contenido del trabajo es totalmente mentalizado (Berardi Bifo, 2003). Esto quiere decir que el trabajo que produce valor es la innovación, proceso por completo mental y que luego se traduce manualmente en distintos idiomas y lenguajes informáticos a diversas máquinas dirigidas automáticamente. Las tecnologías de la información o telemáticas -como las denominan otros (Berardi Bifo, 2003) - abren toda una perspectiva novedosa en torno al trabajo y a las formas de valorización del capital.

A principios de la década del noventa, comenzó a tomar forma una ideología de la virtualidad que preparó un cóctel entre cierta idea de futurismo tecnológico, decepción y caída del socialismo real, tesis del fin del trabajo y el fin de las ideologías y una excitación liberal en torno a las potencialidades del individuo. Esto se sumó a la expansión veloz de Internet, un territorio virtual que prometía en sus comienzos la plena libertad, la horizontalidad, la liberación de las jerarquías, la gratuidad, etc. Esta utopía se fue 
deteriorando -o nunca fue tal-, para dar paso al avance de las grandes corporaciones, las operaciones de la algoritmización, el dataísmo, el googleísmo, el business intelligence y las diversas coacciones de las multinacionales de escala global (García Canclini, 2018; Lins Ribero, 2018; Reygadas, 2018).

Las empresas de tecnología informacional son el resultado del fructífero encuentro entre el capital financiero y el trabajo cognitivo de alta productividad. En América Latina, estas corporaciones, denominadas como "unicornios", intensivo de tecnología que aprovechan los costos bajos de trabajo y una fuerza laboral formada con el más alto ratio de dominio de manejo de los lenguajes informáticos.

Mercado Libre es el unicornio argentino por excelencia. Sus comienzos abonan al transnacional mito del garaje en el que se inscriben varias de las grandes estrellas de Silicon Valley, como Facebook, entre otras. Según el propio Marcos Galperin -dueño y CEO de la empresa-, "prendieron el sitio con cuatro amigos desde unas cocheras" en 1999 y "sabíamos que teníamos el potencial de construir algo muy grande ya que estábamos convencidos de que Internet cambiaría el mundo para siempre". MeLi, como se la denomina en la nomenclatura bursátil, se expandió aceleradamente, aunque funcionó durante siete años con déficit operativo. Recién en 2006 comenzó a dar ganancias y un año después empezó a cotizar en bolsa. En la actualidad, su relevancia es indiscutible. Desde 2017 se convirtió en la empresa de mayor valor en la bolsa de Estados Unidos (NASDAQ), con una cotización mayor a la de YPF -la principal empresa Argentina- de alrededor de 12000 millones de dólares. Ese año, sus ventas alcanzaron los 2334 millones de dólares. Se encuentra entre las 50 páginas web más visitadas del mundo y tiene presencia en 19 países. En 2019, registró 45 millones de usuarios únicos.

Su objetivo central es el desarrollo en América Latina, pero su casa matriz, base de su desarrollo tecnológico, se encuentra en Argentina. La sede principal se sitúa en Capital Federal (oficinas de 26000 metros cuadrados, inauguradas recientemente) pero cuenta con sucursales también en San Luis, Santa Fe, Córdoba y Mendoza. En el total de su plantilla de trabajadores, Argentina representa el 41\%, con aproximadamente 4000 empleados, número que se encuentra en una tendencia creciente a pesar del contexto de crisis económica.

La compañía tiene varias facetas: el e-commerce (o market place), es decir la compraventa de productos por Internet, que es el servicio por el cual se hizo masiva; mercadoenvíos, que atiende la logística de distribución de ese intercambio comercial y la que tiende aceleradamente a posicionarse como el cuore del esquema de negocios de la empresa, Mercado Pago. Esta última involucra las áreas de Mercado Créditos y Mercado Inversiones, con buena perspectiva de diversificar y ampliar los servicios financieros, que en el último año vienen creciendo vertiginosamente.

Por otra parte, la empresa en sí misma y particularmente su CEO, Marcos Galperin, se han ubicado como la mayor referencia nacional de las "empresas del futuro", basadas en un alto desarrollo tecnológico (el manejo de Big Data y Learning Machine) asociado al ecosistema financiero. En esa dirección, se ha sido posicionado como ejemplo a seguir tanto al interior del propio mundo empresario local como del anterior gobierno macrista, que supo promocionarlo y defenderlo enfáticamente como caso paradigmático del empresariado deseable.

MeLi se presenta además como la condensación del discurso de la meritocracia y el emprendedurismo como base del éxito; su robusta filosofía empresarial es un muy buen caso testigo para acercarnos a la comprensión de las bases, implicancias y modos de funcionamiento de este relato que ha ganado tanto terreno en la subjetividad contemporánea.
1. Se les llama unicornios a las empresas basadas en el uso intensivo de la tecnología, que comienzan como starts-up y en períodos de tiempo relativamente cortos alcanzan una cotización superior a 1000 millones de dólares en los mercados de inversión privada.

2. Se trataba de las cocheras de una torre familiar. Marcos Galperin es hijo de Andrés Galperin, dueño y CEO de la curtiembre multinacional SADESA. 
El propósito del artículo es analizar la fuerza de trabajo que se produce y reproduce en un espacio laboral tan particular como es la industria del software y, en particular, en esta empresa estrella en e-commerce en Latinoamérica, de origen nacional. Específicamente, nos interesa abordar las significaciones acerca del trabajo que realizan los trabajadores y las trabajadoras en Mercado Libre, comprendiendo que estas se encuentran en una tensión constante entre las políticas empresarias, los procesos de pedagógicos de producción de una determinada fuerza de trabajo y las agencias de los sujetos. La pretensión hegemónica empresaria consiste en que la doctrina managerial se configure como parte de los sentidos apropiados y naturalizados por los trabajadores y las trabajadoras. En este sentido, indagamos también en las formas de resistencia a estas pretensiones que han surgido desde el mundo gremial, y sus tensiones y desafíos en un nuevo escenario laboral que promete ser predominante en un futuro cercano.

En este artículo desarrollamos tres apartados. En el primero de ellos interesa analizar la construcción de un nosotros y otro por parte de la empresa para definir los sentidos del trabajo normativizados: por un lado, se configura un nosotros asociado fuertemente a los valores del emprendedorismo y la meritocracia y, por otra parte, otro que no se adapta al ecosistema laboral asociado a viejas formas de organización del trabajo. En el segundo apartado, avanzamos en el análisis acerca de las tensiones sindicales y las dificultades de construcción gremial frente a un colectivo de trabajo donde la meritocracia y el emprendedorismo se consolidan como valores vitales. En particular, focalizamos en la organización gremial Unión Informática. Finalmente, en tercer lugar, retomamos los principales ejes, conceptos y hallazgos del análisis en el bloque de consideraciones finales.

Para este artículo nos hemos centrado en una aproximación cualitativa sobre un trabajo de investigación iniciado en 2017 hasta la actualidad. En este trabajo de campo realizamos entrevistas (un total de 29) a trabajadores y trabajadoras de distintos escalafones entre 2018 y 2019. Por otra parte, se hizo particularmente fértil la estrategia de observación participante en las oficinas de la empresa en la Ciudad Autónoma de Buenos Aires, la cual nos permitió relevar y sistematizar in situ prácticas y relaciones laborales que de otra manera no hubiéramos podido registrar. Por último, hemos realizado una compilación, sistematización y análisis de material secundario (notas periodísticas sobre la empresa y entrevistas periodísticas a Marcos Galperin en distintos contextos) y producción fotográfica.

\section{Nosotros innovadores y creativos vs. los otros conformistas y con- flictivos}

Los procesos cognitivos se han vuelto la mercancía por excelencia en las industrias de software. En este nuevo marco, la extracción de ganancias basada en el conocimiento y los procesos de innovación son el factor principal de la acumulación de capital. La pregunta es: ¿qué fuerza de trabajo produce y reproduce una empresa como Mercado Libre en relación con la extracción de conocimiento y la innovación? Los procesos de subjetivación del trabajo atraviesan campos sumamente complejos en los contextos de tecnologías telemáticas. La noción de productividad se vuelve aleatoria y con altos grados de incertidumbre. La producción de valor está indisociablemente atada a la creatividad y la innovación, y en tal sentido, está sujeta a mayores vicisitudes que otros trabajos de características fabriles. Sobre todo, las empresas afrontan la difícil tarea de controlar los tiempos de producción. No todas las horas de un trabajador o trabajadora cognitivo frente a un teclado son tiempos de producción. Los estados mentales y/o emocionales de los trabajadores/as son claves en estos procesos. En este universo laboral, las jornadas de trabajo se extienden indefinidamente y se hacen difusos los límites de los tiempos de no trabajo. El teléfono de bolsillo o celular desempeña funciones 
vitales para una forma de organización del trabajo hiperflexible en la jornada laboral, orientado a objetivos de trabajo y organizado en equipos interconectados.

Mercado Libre ha construido una serie de principios rectores para el desempeño de las tareas por parte de los trabajadores/as. La empresa llama a estos principios ADN Mercado Libre o MeLi. Este ADN se desarrolla en cinco preceptos: "se compite en equipo para ganar"; "se trabaja en beta continua"; "se emprende tomando riesgos"; "se ejecuta con excelencia"; y "se da el máximo divirtiéndose". Estos cinco preceptos que forman un ADN traducen de manera orgánica y sistemática los sentidos empresarios en la constitución de una fuerza de trabajo particular. En primer lugar, llama la atención la referencia biologicista. Al preguntar a una programadora joven sobre qué es el ADN de Mercado Libre, obtenemos la siguiente respuesta:

\section{Investigador: ¿A qué llaman ADN?}

Respuesta: Son pautas y conceptos por los que se rige toda la empresa. Por ejemplo, se compite en equipo para ganar, siempre estamos en beta continua, aprendemos asumiendo riesgos...ese tipo de cosas. Es una forma de convivencia que hay acá. El tema es que hay algunos que no incorporan el ADN, no se adaptaban... esos van cayendo... se van yendo. (Entrevista a programadora, ciudad de Buenos Aires, 12 mayo de 2018)

Como podemos apreciar en la respuesta, algunos se adaptan, otros no. Opera una suerte de "selección natural" - continuando con la metáfora biologicista- que permite identificar a aquellos sujetos con potencial de adaptación y a quienes no están aptos. La pregunta que nos surge inmediatamente es ¿quiénes son los aptos y quiénes no? En este sentido, se delimita un nosotros emprendedores y meritocráticos frente a unos otros conformistas y conflictivos.

\section{Emprendedorismo y meritocracia}

Cuando realizamos trabajo de campo en la empresa Mercado Libre, una de las preguntas que hicimos sistemáticamente a los distintos trabajadores/as que hemos entrevistado fue “¿cuándo les llegó la tecnología en su vida?”. Las respuestas arrojaron diversas informaciones más que interesantes para comprender el universo laboral que estamos estudiando. Lo primero y lo más elocuente son los procesos de construcción generizados que constriñen a la tecnología: a los varones les llega la computadora o cualquier otro dispositivo en los primeros años de su vida, generalmente en los comienzos de la escolarización primaria. En cambio, a las mujeres la tecnología les llega al finalizar los estudios secundarios o incluso en la universidad. No pretendemos ofrecer una explicación a este tema, ya que excede el planteo del presente artículo, pero resulta importante dejarlo explicitado. La otra cuestión interesante es analizar los sentidos del trabajo que tienen los sujetos entrevistados. Para entenderlos, no solo hay que comprender las trayectorias actuales en Mercado Libre, sino que los significados presentes se van construyendo y reconstruyendo a partir de una compleja relación de acontecimientos que tienen que ver con ese acceso a la tecnología, los itinerarios de trabajo y los procesos de subjetivación que se configuran a lo largo de la vida.

La "codificación explícita" -al decir de Gaudemar (1991)- expresada en el ADN de Mercado Libre se vincula a imperativos adquiridos anteriormente al ingreso de la empresa e incluso al mundo del trabajo, en diversas interacciones sociales previas, que van perfilando un sujeto outsider o insider. Toma sentido en los itinerarios de vida de los entrevistados/as las ideas del mérito y el emprendedurismo: difícilmente escindibles una de la otra. 
Los siguientes fragmentos de entrevista detallan lo que postulamos:

Pregunta: ¿Y cómo te llegó la tecnología a vos?

Respuesta: La tecnología me llega de chico porque mi viejo tenía un taller de reparación de electrodomésticos en casa y de muy chico le llevaron para arreglar una de esas computadoras portátiles que se conectaban a la tele, te estoy hablando en el año 86, 87. Yo era muy chico, tenía 6 años... Y un día le trajeron esas computadoras portátiles que se enchufan a la tele y él no sabía cómo probarla. Y me la dio, la enchufó y lo dejó ahí y se fue, y yo me quedé ahí parado con ese bicho. Y creo que a partir ese día... nunca me puedo olvidar de ese día. Yo ese día vi ese aparto y dije, yo quiero, yo quisiera por lo menos saber para qué es cada uno de esos botones. $Y$ me acuerdo que desde ahí le dije a mi viejo, "cuando lo lleves al señor que te lo trajo ¿me podés llevar?”. "Sí, dale”. Y fuimos. Me fui con mi viejo a entregar el producto, a darle la computadora ya arreglada a esta persona. Me acuerdo que caemos al tipo que le arreglamos la computadora, y me mira porque yo iba viendo la cajita porque yo estaba esperando que el tipo la enchufe y la use porque yo quería ver cómo se usaba. Entonces el tipo va la enchufa y me dice, “¿qué pasa?” Me dice "te gusta mucho", y yo me paré al lado y le digo "sí, la verdad que yo quiero ver qué es eso". “¿No querés venir y te enseño?”. A mí se me abrieron los ojos, yo era chico y eso era como ahhhhh, le empecé a llorar a mi papá si me dejaba, si me dejaba, vivíamos en frente, le dice “¿me vas a cobrar algo?”. “No, no, que venga y mire cuando yo la uso”.

Pregunta: ¿Y qué computadora era?

Respuesta: Eran de esas tipos la Commodore 64. Y empecé a ir los sábados a las 3 de la tarde y el señor ese me iba enseñando una tecla cada vez que iba, y yo lo que le decía "Es que yo solamente quería mirar". Y yo lo que hacía era mirar, mirarlo, y veía lo que escribía y me fui metiendo en eso. Y a partir de ahí empecé a hacer lectura de ese tipo de cosas. A la edad de 10 me di cuenta que tenía que aprender inglés. Y me metí a aprender inglés, mis viejos no tenían guita para mandarme ni a un curso de inglés ni a un curso de computación ni nada. Y me empecé a comprar en aquel tiempo el Larousse, una línea de diccionarios, que venían con el diario $L a$ Capital de Rosario, que venía en tomitos coleccionables, y empecé a conseguir de esos, empecé a juntar los vecinos, mi abuela, mi abuelo, todos desde todos sabían que el nieto de ella estaba coleccionando esos diccionaritos y ella me conseguía. Porque venía con el diario gratis, hasta que conseguí la colección completa, y me leí la colección completa de todos los diccionarios. Y alrededor de la edad de 13 ya podía escuchar y leer inglés, digamos. Y a partir de ahí tuve la posibilidad de sentarme ante un manual de programación y ponerme a entender y a programar. Y a los 15 años ya podía desarrollar por mi cuenta sistemas. (Entrevista a Jefe de equipo, Ciudad de Buenos Aires, 3 de junio de 2018)

Una programadora nos relata el punto de inflexión donde aparece la tecnología en su vida:

Pregunta: ¿Y cómo te llegó la tecnología?

Respuesta: A los 11 años le armaba y le desarmaba las radios a mi abuelo, me acuerdo... cuando tenía 11012 años me regaló una radio mi abuelo y yo lo primero que hice con la radio fue sacarle las herramientas y desarmarla toda. Fue lo primero que hice, y puse al lado la radio de mi abuelo desarmada, que era igual a la mía, y tuve... no te miento, debo haber estado dos, tres meses hasta que logré armarla de vuelta y funcionó. A esa edad me empezaron a gustar los aparatos, digamos ahí. Nada, después cuando tuve la primera computadora fue natural. 
Pregunta: ¿A qué edad tuviste la computadora?

Respuesta: La computadora yo la tuve a los 16 años. Era una PC, era una Pentium. Lo primero que hice cuando mi viejo fue al escritorio con la computadora fue desarmar todo el gabinete. Y le empecé a meter cosas y hacía todo yo y me ponía a buscar a ver cómo podía hacer tal cosa, ya a esa altura ya sabía que quería estudiar algo que tuviera que ver con sistemas, me empecé a dar cuenta que me gustaba más la parte de sistemas que lo que era armar y desarmar, si bien siempre fui de hacer eso de armar y desarmar, la parte de sistemas me empezó a gustar mucho. Me di cuenta que tenía facilidad para muchas cosas también, entonces viene de chica el tema, siempre me gustó. Muy rápido me fui a vivir sola... a los 19 me mudé... siempre fui muy independiente. Muy distinto a mis hermanas. (Entrevista a programadora junior, Ciudad de Buenos Aires, 19 de mayo de 2018)

Como es posible observar en los dos fragmentos de entrevista que recrean los entrevistados/as, desde el presente -vale esta aclaración-, se hace explícito en los relatos un fuerte sentido de la iniciativa, la creatividad, la curiosidad, la habilidad y el orgullo del espíritu emprendedor. En ambos relatos aparece un despertar de curiosidad a partir de un objeto que encierra en cierta forma la idea de tecnología: puede ser el armar y desarmar una radio o un televisor, una Commodore 64 o una PC Pentium. A partir de allí, el relato se carga de un imperativo de autonomía, creatividad e innovación constante en la idea del hacer. Los sujetos reaparecen en los relatos, tanto de la programadora como del jefe de equipo, como propiedad de sí, potenciados en sus individualidades. Aunque, si bien aparecen en ambos relatos la familia y hasta los vecinos como parte de ese proceso de empoderamiento, se expresan como un contexto donde el centro de la escena son las capacidades activas del individuo emprendedor potenciadas en su accionar del hacer. La creatividad como potencia liberada es parte esencial de la transformación de la persona que va construyendo su camino frente a los diversos obstáculos e inconvenientes que se le van presentando. El individuo como potencia encarna la primera y la última finalidad. En ambos relatos se evoca un elemento recurrente también en otras entrevistas, que es la construcción de la autosuperación. El emprendedurismo amalgama esa cadena de sentidos que los sujetos entrevistados van evidenciando en sus trayectorias previas al ingreso de un itinerario laboral, y la aparición de la tecnología en sus vidas constituye un momento bisagra.

Continuando con el mismo jefe de equipo del testimonio anterior, su relato desarrolla y afianza un sentido del mérito asociado al trabajo mucho más explicitado:

Cuando trabajaba en Telecom, si había problemas en otros productos, en otras áreas, salía a ofrecer mi ayuda ¿por qué? Porque yo estaba al pedo. Entonces de golpe me convierto como en una especie de referente, me hago como arquitecto de un software sin tener ningún título ni el sueldo de la empresa para hacer esa tarea. Pero sin embargo, ¿por qué lo hacía yo? Porque prefería eso, a estar sentado mirando el techo, yo no quería ser un burócrata más, no quería ser empleado del Estado más. Yo quería crecer profesionalmente, quería conocer nuevas tecnologías, y la empresa me limitaba. Ellos te impedían toda posibilidad de algo nuevo en tecnología. Si hay que hacer tal cosa, ellos te dan un lápiz, una goma y una pala. Hacé eso con lo que tenés; a mí eso no me iba, entonces empecé a armar un grupo de gente con el cual podíamos hacer cosas fuera de las reglas, y ahí me sentía como... podíamos encontrar nuestras propias tecnologías sin que nadie se dé cuenta, podíamos hacer investigación e implementar nuevos productos tecnológicos sin que nadie se dé cuenta, pudimos hacer un montón de cosas muy copadas.

Pregunta: Y puedo suponer que acá es lo opuesto de toda la experiencia que estás contando... 
3. Algunos autores señalan la novedad de esta etapa del capitalismo alrededor de la actividad de los usuarios. Estos pasan a convertirse en "colaboradores" en el proceso de valorización del capital, y tienen un rol estratégico en este sentido. as empresas, al recolectar la información acerca de los gustos y preferencias de los "prosumidores", incrementan el valor en el mercado de sus productos o servicios a partir de la manipulación de esos datos.
Respuesta: Sí, sí. No hay puntos de comparación. En el único punto que vos podés compararlas es que las dos empresas tienen edificios con gente adentro. Pum, fin de la comparación. Yo vine como un pibe que quería volar y me desplegaron las alas en Mercado Libre. A la semana me dijeron: "Flaco, acá necesitamos que abras las alas y vueles alto". Acá no entra cualquiera. Lo ves con las entrevistas, tuve cinco entrevistas para ingresar. No fue que te recomendó tal, sos amigo de tal... entré porque lo merecía. Acá me hicieron pasar por un largo proceso, me hicieron pruebas técnicas muy complicadas... verdaderamente saben en el nivel que estoy laboralmente. Acá estamos los mejores, pero no en el sentido de un título. De hecho, no tengo ningún título. Estamos los que queremos desplegar las alas y volar... estar en beta. [énfasis nuestro] (Entrevista a Jefe de Equipo, Ciudad de Buenos Aires, 22 de mayo de 2018)

Este fragmento de entrevista es más que elocuente y termina de amalgamar la potencia del emprendedorismo con una fuerte noción acerca del mérito. En primer lugar, queremos señalar cierto desliz cuando se refiere a que no "no quería ser empleado del Estado". Esta línea resulta sumamente interesante, ya que el entrevistado estaba relatando su itinerario de trabajo en Telecom, una empresa privada de capitales españoles. No obstante, aparece el sentido del Estado como impedimento, una suerte de summum del neoliberalismo que dispone el derecho a emprender sin ser obstaculizado por ninguna ley o regla. En segundo lugar, se extrema un sentido meritocrático en una especie de deseo personal de buscar siempre más, de liberar las habilidades atadas en su experiencia en Telecom y liberadas en Mercado Libre. ¿En qué consiste esta libertad? Es la capacidad de que el sujeto se transforme constantemente a sí mismo como único responsable de sus logros en un ambiente que posibilite su desarrollo. Y en tercer lugar, reaparece la idea de beta continua, un estado de superación relacionado con el ADN de Mercado Libre. Este estado de superación constante se ve potenciado principalmente a partir de dos características del proceso de trabajo de la empresa: por un lado, Mercado Libre no es una software factory: esto quiere decir que no produce software a pedido de un tercero, sino que produce para sí mismo y en función de sus necesidades corporativas; y por otro, todo lo que se produce en la empresa es siempre un producto inacabado o, más precisamente, un mínimo producto viable (MPV). Es decir, un trabajador/a debe producir un determinado producto con las capacidades mínimas, luego lanzarlo al mercado y testear los movimientos de los prosumidores ${ }^{3}$ (DyerWhiteford, 2004, p. 54), para luego volver a mejorarlo indefinidamente.

Así lo explica otro jefe de equipo:

Mucha gente cuando entra, uno de los puntos que más le cuesta entender es que hay que estar en beta continuo. Si saliste, por ejemplo, terminaste de hacer algo, si saliste de algo nuevo, un producto nuevo, ya tenés que estar pensando cómo lo mejoro. Tenés que armar tareas que te permiten mejorar el producto. Por ejemplo, si vamos a un caso particular que puede ser que cargaste una landing en la cual mostrás una promoción y saliste con una mínima y vas viendo el comportamiento que va teniendo esa landing en el mercado, la vas mejorando, ¿qué le puedo hacer? La puedo hacer que sea más interactiva, le puedo mejorar la calidad de las imágenes, cosa que sea más rápida para el usuario, puede ser que esa landing lo lleve a otro lugar, le agrego tal cosa o le agrego tal otra. Eso, vas todo el tiempo trabajando en beta continua, todo el tiempo, todo el tiempo. Es tu responsabilidad estar en beta. (Entrevista a Jefe de Equipo, Ciudad de Buenos Aires, 3 de junio de 2018)

Este último relato va llevando al paroxismo la idea de las potencialidades individuales, los méritos y la transferencia de la responsabilidad empresarial. La capacidad de estar siempre en beta continua resulta un talento innato en los sujetos: solo hay que querer utilizarla, hay que querer hacer uso de esa potencialidad. ¿De qué capacidades hablamos, concretamente? Que el sujeto al transformar el producto nunca acabado se 
trasforme también a sí mismo. Murillo (2011) plantea que el sujeto deviene empresario de sí. En contraposición a un sujeto en beta continua, encontramos otro bien delimitado puertas adentro de Mercado Libre.

\section{El otro: mediocre, conformista y sindicalista}

Un manager nos relata en una entrevista lo siguiente: "Desvincular es tan importante como contratar. Si tenés una persona conflictiva en la empresa puede hacerte perder todo objetivo de trabajo que esté planificado para un equipo" (Entrevista a Manager, Ciudad de Buenos Aires, 15 de mayo de 2018).

Necesariamente opera en Mercado Libre la construcción de un otro que no se armoniza en el ADN de la empresa, que no se adapta al ecosistema que se propone como ambiente laboral. En contraposición a la persona que está en beta continua, aparece la figura del conflictivo, como aquel sujeto que se niega a producir la transformación necesaria de sí mismo, del producto y, en definitiva, agregar valor a la empresa. En Mercado Libre ese otro se diferencia del sujeto que está en beta continua, no porque carezca de algún tipo de habilidad o título, sino porque principalmente carece de voluntad de reinventarse o de transformarse a sí mismo.

Siguiendo con la idea planteada por el manager, desvincular a un trabajador o trabajadora resulta de suma importancia para mantener un clima de trabajo en que los preceptos del ADN MeLi sean los dinamizadores del ambiente laboral. En este sentido, el proceso de desvinculación, al decir del manager, atraviesa un cauce que puede tener la duración de un año, con diversas advertencias e intentos de reencauzamiento hasta la desvinculación definitiva. Lo que se intenta producir es un cambio de actitud de aquel que está en proceso de ser desvinculado.

Los trabajadores/as son evaluados dos veces por año para conocer si alcanzaron los objetivos propuestos. Si en la evaluación los objetivos no fueron alcanzados, el trabajador o trabajadora es denominado con un bellow expectation (por debajo de la expectativa). Esta situación, en principio, impacta negativamente en el salario. Ahora bien, si en las dos evaluaciones anuales obtiene un bellow expectation, el trabajador/a entra en un proceso de improvement plan (plan de mejoras). Este es el paso previo al despido:

Si te digo que no me gusta lo que estás haciendo, o sea, che tenés una oportunidad, no estás enfocado, no estás proponiendo, el equipo está yendo para allá, y vos estás yendo para otro lado, es que no tenés voluntad. Si con eso no pasa nada, ahí empiezo a intentar cambiar la actitud: contame, ¿qué podemos hacer para que estés mejor? Quiero que lo sepas, o sea yo hoy soy tu jefe y quiero que entiendas que el equipo no está conforme con tu desempeño. Esto es lo que se le llama feedback. O también feedback puede ser algo positivo, che sabés que me encanta lo que estás haciendo, buenísimo, seguí por ese camino, hacelo, contagia al resto. Eso es feedback, lo que se busca es que ese feedback el líder tiene que ser constante, o sea, el feedback con los miembros del equipo tiene que suceder todo el tiempo. $\mathrm{Si}$ una persona no viene enfocada y tuvo feedback bastante durante mucho tiempo y no revirtió la situación, lo que se hace generalmente es... hay dos evaluaciones al año, donde se evalúa si la persona cumple los objetivos, está en las expectativas del cumplimiento de objetivos, superó los objetivos o las expectativas o no las alcanzó. Si está desenfocado y después de mucho feedback no llegó a remontar la situación, tendrá lo que le llamamos un bellow expectation. Esto le pega fuerte en el ajuste de sueldo anual que hay, y por otro lado, si tuvo mucho bellow expectation en las últimas dos evaluaciones se genera lo que se llama un improvement plan, o sea, un plan de mejoras que se acuerdan con la persona para poder revertir la situación, y si al cabo de tres o cuatro meses-depende de lo que dura ese improvement plan-no se 
cumplen, se hace, se decide la desvinculación de la persona del equipo. Y eso ocurre todos los años (Entrevista a Manager, Ciudad de Buenos Aires, 19 de mayo de 2018).

Como se puede visualizar en el relato, el proceso de desvinculación de un trabajador/a atraviesa distintas etapas. Una primera etapa es la advertencia sistemática: "no estás enfocado", "no estás proponiendo", "el equipo está yendo para allá y vos estás yendo para otro lado", "no tenés voluntad". Una segunda etapa, de mayor intensidad, es la transferencia en la responsabilidad al sujeto: “¿qué propones para mejorar?”. Ahí se pone a prueba la voluntad o no del cambio de actitud. Otro momento es explicitar la disconformidad del equipo respecto del desempeño individual. Todo este proceso es gestionado principalmente por el jefe de equipo y se lo llama feedback. Tal como se puede ver en la entrevista, el feedback puede ser en términos "negativos", hacia alguien que no está cumpliendo; o a la inversa, alentar alguien que está cumpliendo exitosamente. Por último, aparece el improvement plan, o plan de mejoras, momento casi irreversible, pero que se constituye como la última posibilidad del sujeto de revertir su situación. El trabajador/a desvinculado es aquel que ya no aporta valor a la empresa.

En este universo laboral, lo que se produce es la innovación del trabajador/a cognitivo. Berardi Bifo (2003) plantea que el contenido del trabajo es íntegramente mentalizado. Con lo cual los procesos de control de los tiempos de producción son mucho más complejos que en otros trabajos más cercanos al modo fabril. Aquí, la emocionalidad, el carácter intelectual, la situación mental juegan un papel crucial en la producción del valor. En este sentido, todo trabajador/a es potencialmente un bellow expectation. Es decir, alcanzar el estado de beta continua no garantiza esa apropiación por tiempo indeterminado. El estado de beta continua hay que validarlo todos los días, aportando valor a la empresa. Por las características del proceso de trabajo, cualquier desajuste puede llevar al trabajador/a ideal al improvement plan. Mantener el rendimiento de los trabajadores/as es uno de los principales problemas de los jefes de equipo:

Nosotros sabemos que cada persona que tenés a cargo de alguna manera es un problema por vencer: todos tienen temas personales, que se enferma, que tiene problemas con la mujer, que se enfermó el hijo, lo que sea. Hay que gestionarlo y ver cómo de alguna manera podés darle la flexibilidad y facilidad como para que se sienta cómodo y pueda trabajar remoto todos los días que necesita, cuidar al hijo que se enfermó o lo que sea, tuvo una contingencia. Todo lo que no sea superprioritario puede esperar. Mi objetivo es mantener a la gente cómoda para evitar que se sienta mal y trate de rotar o de salir de la empresa, que es lo último que queremos. Sabemos que el conocimiento es un montón de valor y hacer que una persona rote por algo, una incomodidad, me parece un totalmente innecesario. (Entrevista a Jefe de equipo, Ciudad de Buenos Aires, 20 de mayo de 2018)

Estos son los problemas que debe enfrentar todos los días un jefe de equipo. Mantener a todos los trabajadores/as en beta continua resulta ser una tarea por demás difícil, dados los imponderables cotidianos que trastocan los "estados mentales" de los trabajadores/as cognitivos. Por ello, el puesto de jefe de equipo es vital: "una de las cualidades fundamentales que un jefe de equipo debe tener: saber qué 'piensan' y qué 'sienten' los integrantes de su equipo" (Palermo, 2018, p. 111). El control de los estados emocionales e intelectuales de los trabajadores/as cognitivos es vital. La flexibilidad de horarios y la autonomía para determinar los ritmos están relacionados con un proceso de trabajo en el que la principal mercancía es el proceso cognitivo.

En este contexto laboral está muy mal visto que alguien no trabaje con la disposición que lo hacen los demás o con la disposición que muestra el equipo de trabajo. Y sobre todo, está muy mal vista la queja: la queja en el trabajo es sinónimo de poca voluntad, 
lo opuesto a la transformación y a la innovación requerida. Es instalarse en una "zona de confort" que resulta ser lo opuesto al estado de beta continua:

El quejoso es un problema en la empresa. Ese que viene y te dice: esto no me gusta, esto es una mierda, o no me gusta trabajar de esta manera... quejándose, quejándose. Ya es una persona que se queja todo el tiempo. Entonces, ¿qué puedo hacer? Ayudarlo a que entienda el feed cultural, que se empape y pueda mejorar y seguir adelante. Ahí ves qué valores puede tener. Por ahí viene con un conocimiento técnico muy fuerte, pero no entiende la cultura de la empresa. (Entrevista a Jefe de Equipo, Ciudad de Buenos Aires, 20 de mayo de 2018)

Profundizando en esta idea, el sujeto conflictivo tiene nombre en Mercado Libre: casualmente y no tanto, es "moyanito":

Mirá, un caso extremo, me pasó, fue uno de los primeros años que estaba como líder acá en Mercado Libre hicieron un acuerdo con una consultora y trajeron como muchos chicos de otros lados. Y me trajeron uno que después acá se pusieron de acuerdo y le pusieron Moyanito

Pregunta: ¿Moyanito?

Respuesta: Sí. Para que te des una idea, venía y me decía, "necesito el viernes tomarme un día”, le digo "Bueno, dale”. Me argumentaba: "porque por ley me corresponde que me den un día por mudanza y todo". Yo le digo, "tranquilo, con que me pidas el día está más que suficiente”. Y así era como que todo el tiempo yendo desde, en vez de ser, de probar indagar, acá trabajamos por objetivos, en equipo, si no podés un día está el equipo para que pueda ayudarte, o sea, eso siempre lo hablamos, pero él como que se manejaba con el reglamento en la mano. (Entrevista a Manager, Ciudad de Buenos Aires, 19 de mayo de 2018)

A diferencia del sujeto en estado de beta continua, aquel que siempre va "más allá", el no conformista, el rebelde frente a cualquier situación de confort que pudiera generarse en el trabajo, el sujeto conflictivo lleva la carga de la falta de voluntad, falta de creatividad, y el conformismo. Sobre todo ese otro es expresión de una forma de organización del trabajo del pasado. Aquí aparece con fuerza la estigmatización de toda construcción gremial. La noción de "Moyanito" no es para nada casual, resulta el arquetipo de sindicalismo en argentina, caricaturizado como bruto, tosco, antitecnológico, fuente de un pasado que nada tiene que ver con la industria del software. La pregunta que abre el siguiente apartado es ¿cómo es la convivencia en estos espacios de trabajo con la organización gremial?

\section{La forma sindical: desfasajes, interrogantes y ensayos}

El gran dinamismo económico que viene mostrando la industria informática, con un crecimiento promedio del $4 \%$ anual en la última década, ${ }^{4}$ supuso un aumento exponencial de la cantidad de trabajadores involucrados en el sector que, entre formales e informales, se calcula en alrededor de 250 mil puestos. De ese total, las estimaciones señalan que solo alrededor de un $25 \%$ de la masa de trabajadores tiene algún tipo de afiliación gremial. Al compás de este crecimiento, se abrió un panorama de disputa sindical que involucra varias dimensiones: la pelea institucional por captar nuevos afiliados desde las estructuras más tradicionales, un accionar profuso del Estado (especialmente desde el ex Ministerio de Trabajo encabezado por Jorge Triaca) para direccionar políticamente este encuadramiento $\mathrm{y}$, por último, el surgimiento de nuevas expresiones de organización sindical, protagonizadas por jóvenes, que intentan
4. Datos de la Cámara de la Industria Argentina del Software (CESSI). Disponible en http://www.cessi. org.ar/. Por otra parte, de acuerdo con los datos del Observatorio del Empleo y Dinámica Empresarial del Ministerio de Trabajo, solo en el sector de Software y Servicios Informáticos, el número de empresas creció más del 50\% en la última década, y el empleo sectorial se incrementó casi un 45\% entre 2008 y 2018. En ese sentido, de trata de uno de los pocos sectores de actividad que crea empleo en un marco general fuertemente recesivo y de destrucción de puestos de trabajo. 
5. La acción estatal se produjo por acción y omisión. Por un lado, una negativa contundente al reconocimiento y el diálogo con las organizaciones ya formadas o en proceso de consolidación que no respondieran directamente a la alineación gobierno-sectores empresarios. Por acción, lo que más se destaca es el intento, pocos días antes terminar su gestión como ministro de Jorge Triaca, de otorgar la personería gremial a AGC a partir de una resolución (contrario al procedimiento legal que indica la realización de compulsa). Esta determinación unilateral no pudo ser sostenida por la propia falta de solvencia de la entidad, que, a pesar del respaldo oficial, no pudo demostrar un mínimo de afiliaciones, a lo que se sumaron las impugnaciones presentadas por las otras asociaciones en disputa. construir una nueva interpelación para sus pares, quienes por edad, perfil profesional y un sentido del trabajo asociado al emprendedurismo y la meritocracia (como analizamos en el apartado anterior), tienden a sentirse naturalmente distantes del mundo gremial (Ventrici, 2018).

En relación con la tensión por el encuadramiento sindical, la disputa entre organizaciones ya consolidadas por la cantidad creciente de trabajadores y los ingentes recursos que estos representarían (se calcula un potencial de más de $\$ 7$ mil millones anuales, sumando cuotas sindicales, obras sociales y aportes patronales) aparece como un indicador sintomático de dos características que atraviesan la situación actual de las instituciones sindicales. Por un lado, vuelve a ponerse de manifiesto el notable grado de fragmentación y dispersión de las estructuras; además, se hacen patentes -como en ningún otro sector de actividad- la inviabilidad y el anacronismo de las normas, formas y prácticas tradicionales para intentar ejercer la representación en formas del trabajo, cada vez más preponderantes y difusas, que no encajan en ningún convenio colectivo, estatuto o normativa ya existente.

Como señalábamos anteriormente, el Estado a través del (ex) Ministerio de Trabajo, especialmente bajo la gestión del presidente Macri, ha sido particularmente activo, y ha operado para tratar de encauzar políticamente a su favor una pelea que entiende fundamental, tanto por la cantidad de trabajadores y de recursos involucrados como por el carácter indudablemente estratégico que el sector informático ocupará, cada vez con más contundencia, en la estructura productiva. ${ }^{5}$

La novedad política, en materia de organización colectiva, es, como decíamos anteriormente, la conformación de un nuevo sindicato, traccionado por militantes muy jóvenes y que fue construyendo niveles importantes de ascendencia en ciertos sectores de los trabajadores informáticos: la Unión Informática (UI).

Los comienzos de la organización se sitúan en una multinacional protagónica a nivel global: IBM, a la que en la UI llaman "el gigante azul”. La gran mayoría de quienes actualmente forman el consejo directivo del sindicato trabajan en IBM y vienen de ese grupo primigenio que impulsó la organización gremial en la empresa a partir de 2009, primero junto con el gremio de telefónicos Cepetel, y que luego se independizó para crear la UI. A partir de entonces, se intensificaron las protestas, fundamentalmente por el descontento salarial. En 2010 tiene lugar la primera elección de delegados y un año después, el 28 de julio de 2011, UI realiza la primera huelga en la empresa, que es, además, la primera medida de acción directa de los trabajadores informáticos en Argentina. Ese día quedó marcado como una fecha mítica en la novela institucional (Hudson, 2011) de esta organización que, en términos formales, arrancó su derrotero en marzo de 2011, con el pedido de la inscripción gremial al Ministerio de Trabajo. Transcurrieron dos años y medio entre ese primer paso y la obtención de ese trámite (en octubre de 2013). Desde los inicios, el "apadrinamiento" de la CGT, en especial de Facundo Moyano, dirigente de la Juventud Sindical, fue clave en el plano del asesoramiento político, jurídico y financiero.

En paralelo a la pelea por el reconocimiento formal, el nuevo sindicato se dio una política de expansión en las empresas del sector, primero y fundamentalmente en el área metropolitana de Buenos Aires y luego en otras grandes ciudades del interior, como Rosario y Córdoba. Hasta el momento, lograron tener presencia en poco más de 40 empresas, con cerca de 1000 afiliados. Por las características de la propia actividad y la evolución reciente del mercado de trabajo, el promedio de edad de los afiliados ronda los 30 años y es una población mayoritariamente masculina. Esta composición se refleja también en el consejo directivo del sindicato, cuyos integrantes tienen un promedio etario subcuarenta, y en el que no hay mujeres. 
Un punto central de esta construcción gremial es su modo de interpelación y el acercamiento al sindicato de estos "trabajadores de nuevo tipo". Por un lado, según analizan los propios dirigentes de UI, el contacto surge, en la gran mayoría de los casos, a partir del agravamiento, primero, de la condición salarial, y en segundo plano (pero de gran importancia), de la precarización de las condiciones de trabajo, sumamente heterogéneas entre las distintas empresas, y cuya desregulación se agudiza por las propias condiciones de la tarea:

El sueldo te va quedando congelado año tras año, eso es lo que nosotros vemos de las empresas que no respetan ningún convenio, ¿qué pasa? Vos entraste con un sueldo bárbaro, te dieron fruta, te hicieron masajes, pero al año siguiente, hay una inflación del 50\% y vos tuviste un aumento del 20\%, los masajes, los juegos, está todo muy lindo pero no te sirven para ir a comprar carne al supermercado. Disney se acaba cuando te llega el recibo de sueldo. (Entrevista a dirigente UI, Ciudad de Buenos Aires, 10 de abril de 2019)

Entre las distintas escalas de trabajadores de las empresas de software, se diferencia claramente una suerte de vinculación "estratificada" con el mundo gremial, en la que, tendencialmente, los sectores más desfavorecidos de la pirámide laboral son los más propensos a considerar la posibilidad de la organización colectiva como recurso. Así lo explica uno de los miembros del Consejo Directivo del sindicato:

Los que suelen acercarse en principio son los que nosotros llamamos la rama aguas ygaseosas dentro de universo de los camioneros, que son los técnicos, los que están en la calle arreglando cajeros, arreglando la maquinita donde vos comprás en el Coto y te la marcan, los chicos que hacen soporte técnico telefónico, los que hacen soporte técnico lo que se llama on site o [...] Esos chicos son lo que suelen acercarse más, ¿por qué? Porque sus salarios son más bajos, porque están en condiciones en general precarias, porque no están laburando en su empresa, están laburando en el sector informático de otra empresa que no les importa mucho, entonces por ahí viene la mayor parte de afiliados y compañeros, después, la rama que sigue que son los desarrolladores, toda esta gente que son los que salen en La Nación, dice nosotros ganamos 100 mil dólares por mes, que tampoco ganan 100 mil dólares por mes, te aseguro que no. Yo soy programador y gano 35 mil pesos, trabajo en IBM. (Entrevista a dirigente de UI, Ciudad de Buenos Aires, 10 de abril de 2019)

Otra marca clave del proceso de construcción gremial de la UI es el trabajo sobre la imagen y la comunicación. En un sector con un perfil, como hemos analizado, de trabajadores y trabajadoras calificados/as muy influenciados por el discurso del emprendorismo y la meritocracia individual y una fuerte y arraigada cultura antisindical -reforzada desde la organización empresarial-, la primera gran tarea de los dirigente de UI fue diseñar una estrategia para "vender" al sindicato desde una estética y una prédica alejada del folklore sindical -aquel que es visto de manera caricaturesca por el sector empresarial de la industria del software- que venciera ese rechazo inicial y permitiera construir los primeros acercamientos con los jóvenes.

La mayoría de los que se acercan tienen entre 25 y 35 años, ya tuvieron dos o tres trabajos, se les pinchó el globito de que van a ser Bill Gates o Apple. Trabajamos mucho la comunicación, no usar palabras como lucha o conflicto, porque no gustan. Al trabajador informático no le podés entrar por el discurso combativo, no tiene ese perfil, salvo que sea alguien que ya viene de ese palo y se da cuenta porque a los minutos te dice "lucha", "compañero". Al principio, la Secretaría de Comunicación era la más grande, porque le habíamos puesto un foco muy grande a nuestra política de comunicación, de publicidad, de marketing, de propaganda. Hoy camina sola, pero nos costó mucho tiempo pensar qué gustaba, qué pegaba más, qué pegaba 
menos. Hicimos ensayos, probábamos diferentes palabras. Lo mismo que les decimos a los chicos: "cuando vayan a la empresa, vayan pintones"; no podés ir con la barba larga, son cosas que uno revisa mucho. Nos gustaría ir en bermudas y en ojotas pero no, no tiene llegada. (Entrevista a dirigente de Ul, Ciudad de Buenos Aires, 14 de diciembre de 2018)

Usar las mismas estrategias de la empresa pero para hacer cosas "buenas" es una de las máximas que repiten varios de los dirigentes y delegados de la UI y cuya puesta en práctica se hace visible en la asimilación de la estética empresarial en su modo de comunicación y publicidad (tanto en las redes como en comunicados y panfletos) y la impronta de las actividades y los dirigentes. Se construye un discurso sindical que no impugna la idea de emprendedorismo o la noción de la meritocracia. Prima un la lógica pragmática, que deja de lado el discurso más ideológico, clasista o tradicionalmente "político" (aunque muchos de sus militantes y dirigentes, personalmente, tengan formación y posturas claras al respecto) a la hora de convocar a los afiliados, y apela más bien a una lógica corporativa desde un "managment sindical".

Nosotros venimos de Disney, falso Disney, venimos de Disney, sabemos que, entonces usamos un montón de técnicas, herramientas, así como las usan ellos, nosotros con nuestros límites y nuestros recursos acotados, usamos lo mismo que ellos, hablamos como te digo, hablamos de otra forma con los compañeros, manejamos redes sociales de otra forma que otros sindicatos. Sí, hablémosles como les habla Galperin, démosle la naranja, traigámoslo acá a la sede sindical y hablémosles de a poco de que, de lo que es ser un trabajador. (Entrevista a dirigente UI, Ciudad de Buenos Aires, 14 de diciembre de 2019)

Por eso, dicen: "lo que nosotros tratamos de hacer es plantear 'esto conviene', que también es completamente valido, es el bolsillo del laburante, es así, te conviene, 'nos conviene estar juntos"'. Desde un discurso empresarial, van construyendo la idea de que no solo son el mérito o el emprendedorismo los sentidos dominantes en el trabajo, sino también el salario, la condiciones de la jornada de trabajo, etc. Esto se conjuga con un planteo también de conveniencia y moderación frente a los empresarios:

Después de que pasan las medidas de fuerza van aprendiendo que nosotros trabajamos muy ordenadamente, somos muy prolijos, no pedimos cosas de más, tampoco de menos, entonces ahí van aprendiendo que está bueno incluso trabajar con los sindicatos, incluso muchas cuestiones de recursos humanos las resolvemos nosotros. (Entrevista a dirigente UI, Ciudad de Buenos Aires, 20 de octubre de 2017)

No obstante, cabe decir que, como bien se refleja en una de las entrevistas a un dirigente de UI, mayormente han podido acceder al sector de "aguas y gaseosas" - usando una metáfora sobre los trabajadores comparativamente más precarizados en la industria del software-, con bajos niveles de interpelación entre trabajadores y trabajadoras de, por ejemplo, las llamadas empresas unicornio, como Mercado Libre. Aquí los controles empresarios antisindicales son más férreos, pero sobre todas las cosas, los sentidos instalados del trabajo alrededor de un nosotros meritorcáctico y emprendedor y otro conflictivo obstruyen en gran medida la penetración de la organización gremial.

\section{Consideraciones finales}

En este artículo nos propusimos analizar las condiciones de producción y reproducción de la fuerza de trabajo en los nuevos contextos de empresas de "economía de plataformas" y su tensión con las lógicas de organización gremial que intentan hacer pie en estos nuevos espacios. 
En primer lugar, pusimos el foco, por un lado, en la construcción managerial que pretende construir una doctrina hegemónica que configure los sentidos del trabajo y que sean apropiados y naturalizados por los trabajadores y las trabajadoras. Para este análisis tomamos el caso de la empresa unicornio más importante de Argentina, Mercado Libre, de referencia local y global para el sector. Enfatizamos en los procesos de construcción de un nosotros y un otro por parte de esta para definir los sentidos del trabajo normativizados y cómo esos imperativos están indisociablemente imbricados con los potentes discursos contemporáneos del emprendedorismo y la meritocracia.

En el análisis de los pilares de la robusta filosofía empresarial de la empresa, los denominados preceptos del ADN MeLi, que traducen de manera orgánica y sistemática los sentidos empresarios en la constitución de una fuerza de trabajo particular (nosotros), destacamos algunos conceptos específicos de este sistema managerial centrado en la autosuperación individual. El que mejor representa el objetivo planteado de la superación permanente es el precepto de beta continua, lo contrario a la instalación del trabajador en una "zona de confort". El estado de beta continua pone en el centro la implicación subjetiva centrada en la competencia, la asunción permanente de riesgos como motivación, la diversión como imperativo. Quienes, de acuerdo con la evaluación permanente de la empresa, no muestran esa disposición y, por tanto, no tienen feedback con su equipo, entra en la categoría de trabajador bellow expectation, que debe ser sometido a un improvement plan para volver a lograr la implicación necesaria para evitar ser desvinculado de la empresa.

Justamente, del lado de los otros, aquellos que, de acuerdo con el discurso empresarial, no se adaptan al ecosistema laboral y que se asocian con viejas formas de organización del trabajo, aparecen los intentos de organización gremial en el sector. Para indagar en este plano, analizamos la experiencia de la Unión Informática, que consideramos la novedad política más importante en lo que refiere a los intentos de interpelación sindical entre los informáticos. Examinamos sus desafíos, estrategias y limitaciones.

En ese sentido, dimos cuenta de una estrategia de aproximación basada en buena medida en la asimilación -en términos comunicacionales- al discurso empresarial, intentando "usar las mismas estrategias de la empresa pero para hacer cosas buenas". Al mismo tiempo, prima una la lógica pragmática, que deja de lado el discurso más ideológico o tradicionalmente "político" a la hora de convocar a los afiliados y apela más bien a una lógica corporativa desde un "managment sindical". Sin embargo, se evidencia como limitación una suerte de alcance segmentado de esta estrategia, que les permite acceder a lo que denominan el "sector de 'aguas y gaseosas" (la base de la pirámide) pero no es efectiva para penetrar en las empresas unicornio, como Mercado Libre, donde la construcción de ese sujeto normativizado por la filosofía empresarial meritocrática y del emprendedurismo funciona como una barrera simbólica de contención para las prácticas de organización colectiva, sumada a los férreos controles antisindicales por parte de los dispositivos manageriales.

Estas reflexiones, indefectiblemente, abren preguntas sobre la efectividad o no de la organización sindical en estos espacios de trabajo. Queda planteado el interrogante de si se trata de un proceso en el que el hiperindividualismo configura un límite a la organización (Montes Cató, 2010) o -en una vuelta de tuerca más compleja- se deduce que la actual fase del capitalismo (cognitivo, informacional, digital), por sus rasgos particulares, colisiona con formas de sindicalización propias de la etapa industrial (Ferpozzi y Zukerfeld, 2012). Quizás la respuesta sea complejizar aún más ambas propuestas aquí planteadas. 


\section{Financiamiento}

Este documento es resultado del financiamiento otorgado por el Estado Nacional, por lo tanto queda sujeto al cumplimiento de la Ley № 26.899. Organismo Financiador: Consejo Nacional de Investigaciones Científicas y Técnicas- CONICET. Buenos Aires, Argentina.

\section{Biografía}

Hernán M. Palermo es Doctor en Ciencias Antropológicas. Investigador del Centro de Estudios e Investigaciones Laborales (CEIL-CONICET-Argentina). Director de la Revista Latinoamericana de Antropología del Trabajo perteneciente al CEIL de Argentina y al CIESAS de México. Director de la Maestría en Estudios Latinoamericanos del Trabajo de la Facultad de Filosofía y Letras, UBA.

Patricia Ventrici es Doctora en Ciencias Sociales. Investigadora del Centro de Estudios e Investigaciones Laborales (CEIL-CONICET-Argentina). Docente (UBA). Vicedirectora de la Maestría en Ciencias Sociales del Trabajo, Facultad de Ciencias Sociales, UBA. 


\section{Q Referencias bibliográficas}

"Berardi Bifo, F. (2003). La fábrica de la infelicidad. Nuevas formas de trabajo y movimiento global. Madrid: Traficantes de Sueños.

"Dyer-Whiteford, N. (2004). Sobre la contestación al capitalismo cognitivo. Composición de clase de la industria de los videojuegos y de los juegos de ordenador. En O. Blondeau et al. (comps.), Capitalismo cognitivo, propiedad intelectual y creación colectiva (pp. 49-62). Madrid: Traficantes de Sueños.

» Ferpozzi, H. y Zukerfeld, M. (2012). ¿Puede el sindicalismo adaptarse al trabajo informacional? Un análisis de la relación entre trabajadores informáticos y el mundo gremial. En L. Dughera, G. Yansen y M. Zukerfeld (comps.), Gente con códigos. La heterogeneidad de los procesos productivos de software (pp. 279-323). Buenos Aires: Universidad Maimónides, Editorial Científica y Literaria.

" García Canclini, N. (2018). Cómo investigar en la era comunicacional del capitalismo. Desacatos, 56, 90-105.

"Gaudemar, J. P. (1991). El orden y la producción. Nacimientos y formas de la disciplina de fábrica. Madrid: Trotta.

"Hudson, J. P. (2011). Acá no, acá no me manda nadie: empresas recuperadas por obreros 2000-2010. Buenos Aires: Tinta Limón.

"Lins Ribero, G. (2018). Impactos y dinámicas del capitalismo electrónico-informático: un dossier. Desacatos, 56, 16-33.

» Montes Cató, J. (2010). Condiciones de explotación y fuerza de trabajo en la industria del software. En El trabajo en el capitalismo informacional. Los trabajadores en la industria del software (pp. 69-101). Benavidez: Poder y Trabajo.

»Murillo, V.(2011). La nueva cuestión social y el arte neoliberal de gobierno. Cátedra Paralela, 8, 9-32.

»Palermo, H. (2018). Masculinidades en la industria del software en Argentina. Revista Internacional de Organizaciones, 20 (Género, trabajo y organizaciones), 103-121.

》 Reygadas, L. (2018). Dones, falsos dones, bienes comunes y explotación en las redes digitales. Diversidad de la economía virtual. Desacatos, 56, 70-89.

» Sadin, E. (2018). La silicolonización del mundo. La irresistible expansión del liberalismo digital. Buenos Aires: Caja Negra.

»Ventrici, P. (2018). La nueva camada. Experiencias de renovación sindical protagonizadas por jóvenes en la última década. Revista de Estudios Latinoamericanos del Trabajo (RELET), 3, 97-124. 